\title{
Reduction of Raf Kinase Inhibitor Protein Expression is Associated with Lymph Node Metastasis in Resectable Non-small Cell Lung Cancer
}

\author{
Huang Yan $^{1}$, Lin Guoqiang ${ }^{2}$, Chen Shengxi ${ }^{2}$, Deng Zhenghao ${ }^{3}$ and \\ Huang Lingjin ${ }^{*}, 2$ \\ ${ }^{I}$ Department of Infectious Disease, Xiangya Hospital, Central South University, Xiangya Road, Changsha, China \\ ${ }^{2}$ Department of Cardiothoracic Sugery, Xiangya Hospital, Central South University, Xiangya Road, Changsha, China \\ ${ }^{3}$ Department of Pathology, Xiangya Hospital, Central South University, Xiangya Road, Changsha, China
}

\begin{abstract}
Introduction: Raf kinase inhibitor protein (RKIP) had been identified as one of prognostic indictor in various malignant diseases. Association of RKIP expression and the clinical-pathological features were not investigated in patients with resectable non-small cell lung cancer (NSCLC).
\end{abstract}

Materials and Methodology: 159 sectioned samples from surgical NSCLC patients were investigated by immunohistochemistry in order to reveal the associations between RKIP expression and clinical-pathologic features.

Results: Statistically, Lower RKIP expression level was found in the group with higher N stage $(\mathrm{P}<0.01)$ and higher TNM stage $(\mathrm{P}<0.05)$. No significant correlation was observed between RKIP expressions and histologic type $(\mathrm{P}>0.05)$ and tumor size $(\mathrm{P}>0.05)$.

Conclusions: Down expression level of RKIP was found relating to lymph node metastasis in resectable NSCLC patients in this study.

Keywords: Raf kinase inhibitor protein, non-small cell lung cancer, lymph node metastasis.

\section{INTRODUCTION}

The Raf/MEK/ERK (Raf/mitogen-activated protein kinase kinase/extracellular signal-regulated kinase) pathway plays a critical role in cell proliferation, apoptosis and malignant transformation [1, 2]. Over-activation of the Raf/MEK/ERK cascade, which may be caused by components mutation or altered expression of regulators of the pathway, has been frequently observed in human cancer. Raf Kinase Inhibitory Protein (RKIP) is a member of the phosphatidylethanolamine-binding protein family which has been shown to inhibit Raf-1 activity [3] and render Raf/MEK/ERK cascade alteration. In prostate cancer study, RKIP has been identified as a metastasis suppressor $[4,5]$ that RKIP expression was detectable by immunohistochemistry in all noncancerous prostate tissues and decreased to an undetectable level in all prostate cancer metastases. And metastatic properties of prostate cancer cells could be affected by RKIP expression level [4]. Similar results had been revealed in colorectal cancer, breast cancer, malignant melanoma, thyroid cancer and liver cancer [6-11].

Lung cancer is the most common cancer and the leading cause of cancer-related death worldwide. Not too many non-

*Address correspondence to this author at the Department of Cardiothoracic Sugery, Xiangya Hospital, Central South University, Xiangya Road, Changsha, China; Tel: +8673184323003; E-mail: drhuanglj@gmail.com small cell lung cancer (NSCLC) patients are suitable for surgery when diagnosis was confirmed, and prognosis of these patients always varied after surgery. So it is important to find prognostic marker and initiate adjuvant therapy after surgery in these patients. Recent findings demonstrated that phospho-RKIP was a predictive indicator of lung cancer survival [12]. However, there is no research on the relationship of RKIP expression and clinical-pathologic features of surgical lung cancer patients.

The aim of this study was to determine the correlation between RKIP expression and clinical-pathologic features in resectable NSCLC. 159 tissue samples from resectable NSCLC were investigated using immunohistochemistry.

\section{MATERIALS AND METHODS}

\section{Patient Population and Clinical Specimens}

From January 2004 to May 2006, 159 patients with resectable NSCLC underwent curative surgical resection at Department of cardiothoracic surgery, Xiangya medical school Xiangya Hospital. None of the patients had received preoperative chemotherapy or radiotherapy. Extensive mediastinal lymph node dissection was performed during the surgery. Resected specimens were sent to pathology department for histopathological and immunohistochemical examination. The study was approved by the Medical Ethics and Human Clinical Trial Committee at Xiangya Hospital, and patients gave the oral or written informed consent. 
Table 1. Correlation of RKIP Expression to Clinical-Pathologic Features of Non-Small Cell Lung Cancer

\begin{tabular}{|c|c|c|c|c|c|}
\hline$>60$ & 84 & $14(16.7 \%)$ & $29(34.5 \%)$ & $41(48.8 \%)$ & 0.986 \\
\hline$<60$ & 75 & $13(17.3 \%)$ & $25(33.4 \%)$ & $37(49.3 \%)$ & \\
\hline Male & 95 & $16(16.8 \%)$ & $32(33.7 \%)$ & $47(49.5 \%)$ & 0.992 \\
\hline Female & 64 & $11(17.2 \%)$ & $22(34.4 \%)$ & $31(48.4 \%)$ & \\
\hline \multicolumn{6}{|l|}{ Histopathology } \\
\hline Squamous cell carcinoma & 102 & $16(15.7 \%)$ & $38(37.3 \%)$ & $48(47.0 \%)$ & 0.491 \\
\hline II & 67 & $11(16.4 \%)$ & $21(31.3 \%)$ & $35(52.2 \%)$ & \\
\hline III & 62 & $13(21.0 \%)$ & $29(46.8 \%)$ & $20(32.3 \%)$ & \\
\hline \multicolumn{6}{|l|}{ Tumor Size } \\
\hline$\leq 3 \mathrm{~cm}$ & 42 & $8(19.0 \%)$ & $14(33.3 \%)$ & $20(47.6 \%)$ & 0.917 \\
\hline$>3 \mathrm{~cm}$ & 117 & $19(16.2 \%)$ & $40(34.2 \%)$ & $58(49.6 \%)$ & \\
\hline \multicolumn{6}{|l|}{ Lymph Node Involvement } \\
\hline No & 30 & $2(6.7 \%)$ & $4(13.3 \%)$ & $24(80.0 \%)$ & $<0.01$ \\
\hline N1 & 78 & $12(15.4 \%)$ & $26(33.3 \%)$ & $40(51.3 \%)$ & \\
\hline
\end{tabular}

Details of patient's clinical characteristics including age, gender, tumor size and histological type were recorded. The stage of the primary tumor was determined by reviewing both the surgical and the pathological reports according to the international staging of lung cancer [13]. Clinicalpathological variables of the subjects are summarized in Table 1.

\section{Immunohistochemistry}

Immunohistochemical staining for RKIP was carried out using the SuperPicTure ${ }^{\mathrm{TM}}$ Polymer Detection kit (Zymed, San Francisco, CA) according to the manufacturer's instructions. The slides with $4-\mu \mathrm{m}$ sections of paraffin tissue blocks were dried at $60^{\circ} \mathrm{C}$ for 30 minutes, treated with xylenes, then dehydrated in alcohol. Endogenous peroxidase was blocked with $3 \% \mathrm{H}_{2} \mathrm{O}_{2}$. Microwave treatment of the slides was performed for $15 \mathrm{~min}$ in $0.01 \mathrm{~mol} / \mathrm{L}$ citrate buffer ( $\mathrm{pH}$ 6.0). After incubating the RKIP antibody with the tissue at 1:100 dilutions, the HRP polymer was added, and after a wash step, the DAB chromogen is then added to visualize the antibody binding. Slides were counterstained with hematoxylin.

\section{Evaluation of Immunohistochemistry}

All sections were examined microscopically and scored by two investigators who were blind to the clinical data. Expressions of RKIP were evaluated according to the percentage of positive cells and staining intensity [6]. Briefly, the score is the sum of the percentage of positive cells $(1$, less than $25 \%$ positive cells; $2,26 \%$ to $50 \%$ positive cells; and 3, more than 50\% positive cells) and the staining intensity ( 0 , negative; 1 , weak; 2 , moderate; 3 , strong). Sums between 0 and 2 were scored as weakly positive, sums of 3 and 4 were scored as moderate positive, and sums of 5 and 6 were scored as strong positive.

\section{Statistical Analysis}

The Chi square test was used to examine the association between the RKIP expression status and clinical-pathological features. Differences were considered significant when $P \leq$ 0.05. Statistical analysis was performed using SPSS statistical software (Chicago, IL).

\section{RESULTS}

\section{Immunohistochemical Analysis of RKIP in NSCLC}

The immunoreactivity against RKIP was mainly in the cytoplasm (Fig. 1). Expression of RKIP and correlation with clinical-pathologic features was shown on Table 1. No significant correlation was found between RKIP expression and sex, age and histological types $(P>0.05)$. RKIP positivity was detected nearly equivalently in cases of tumor diameter $>3 \mathrm{~cm}$ and $\leq 3 \mathrm{~cm}$ respectively which indicated no correlation between RKIP expression and tumor size of NSCLC $(P>0.05)$. Decreasing expression of RKIP was 

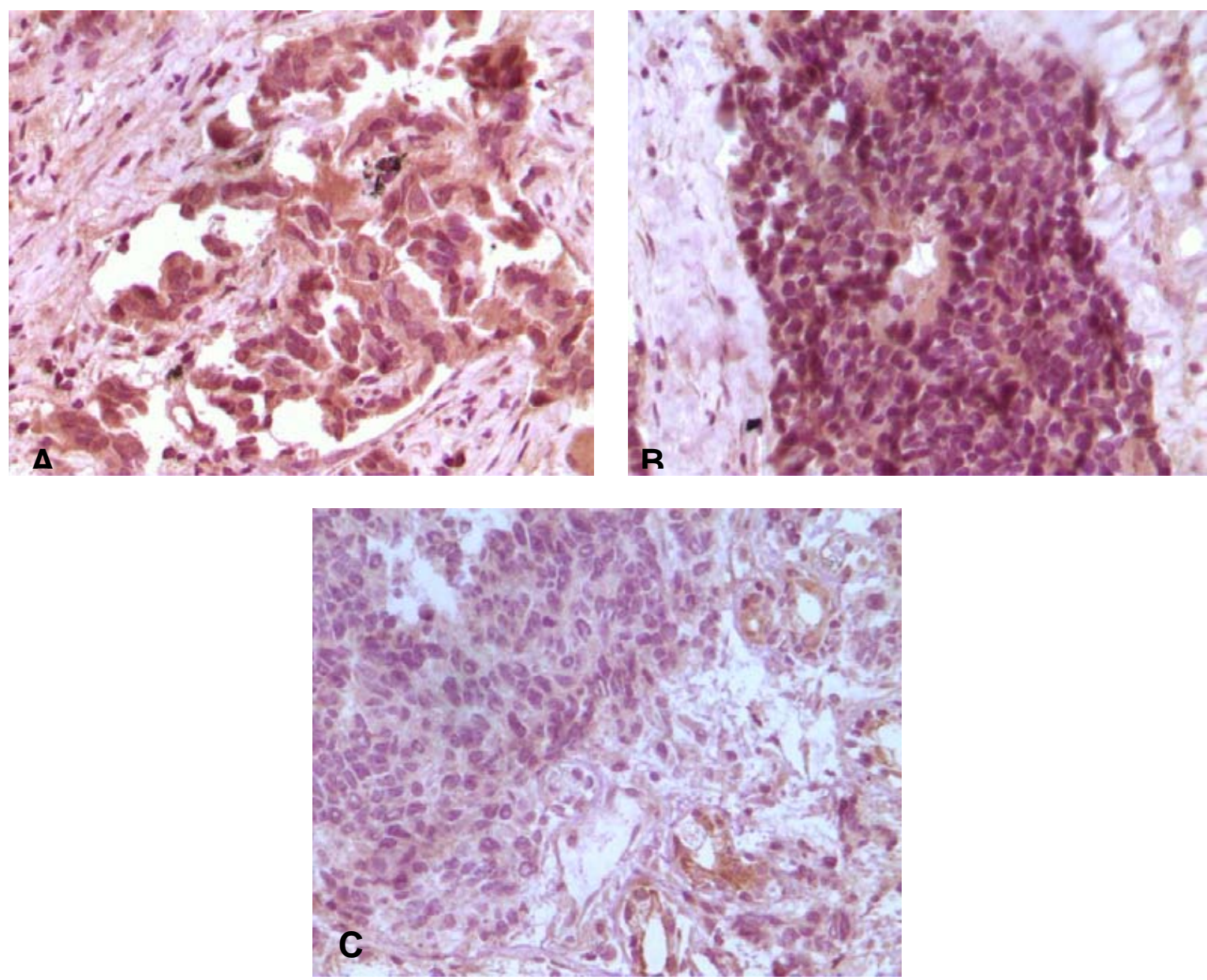

Fig. (1). Immunohistochemical staining of RKIP in NSCLC. A: Strong positive staining of RKIP in lung adenocarcinoma, B: in lung squamous cell cancer, $\mathbf{C}$ : Weakly positive staining in lung squamous cell cancer.

associated with higher $\mathrm{N}$ stage $(P<0.01)$ and TNM stage $(P<0.05)$. Significant higher RKIP expression were found in N0 patients compared with N1 patients $(P=0.025)$, and higher RKIP expression in N1 patients compared with N2 patients $(P=0.026)$.

\section{DISCUSSION}

In resectable lung cancer patients, lymph node metastasis is one of the most important prognostic indictors. In this study, 159 patients with resectable NSCLC were analyzed and the negative correlation between RKIP expression and lymph node metastasis was found.

RKIP plays important role in cancer cell growth, apoptosis and transformation by affecting several protein kinase signaling cascades such as Raf/MEK/ERK, G-protein signaling and NF-kappaB signalling [1, 14-16]. RKIP was first identified as a novel metastasis suppress marker in prostate cancer [4]. Its expression in prostate cancer metastases was down-regulated or undetectable. In addition, metastatic properties of prostate cancer cell lines could be changed by altering cell RKIP expression [4]. These results demonstrated that loss of RKIP was associated with the development of cancer metastases. RKIP loss could lead to chromosomal instability which may account for the RKIP loss related metastases [17].
In this study, lower expression of RKIP was associated with higher $\mathrm{N}$ stage and TNM stage. Significant higher RKIP expression were found in N0 patients compared with N1 patients, and higher RKIP expression in N1 patients compared with $\mathrm{N} 2$ patients. These results indicated that reduced expression of RKIP was correlated with lymph node metastasis in NSCLC patients. Lymph node metastasis always happens before distant metastasis and it is an important predictive factor for cancer prognosis $[18,19]$. In clinic, it is difficult to detect occult early metastasis which accounts for the poor prognosis of lung cancer. In our investigation, negative correlation of RKIP expression with lymph node metastasis was detected in the operable NSCLC patients. It indicated that RKIP may be served as a biomarker of lymph node metastasis of NSCLC which is clinically important for judging the prognosis of lung cancer patient and may provide additional information for adjuvant treatment on these patients. In this study, there was no distant metastasis in these patients; further investigation is needed to analyze the correlation of RKIP expression and distant metastasis in the future.

\section{CONCLUSION}

In summary, given the high mortality of lung cancer, the relationship between RKIP expression and lymph node metastasis provided new clues to understand the cause of metastasis. 


\section{CONFLICT OF INTEREST}

The authors confirm that this article content has no conflicts of interest.

\section{ACKNOWLEDGEMENTS}

Declared none.

\section{REFERENCES}

[1] Odabaei G, Chatterjee D, Jazirehi AR, et al. Raf-1 kinase inhibitor protein: structure, function, regulation of cell signaling, and pivotal role in apoptosis. Adv Cancer Res 2004; 91: 169-200.

[2] Keller ET, Fu Z, Brennan M. The role of Raf kinase inhibitor protein (RKIP) in health and disease. Biochem Pharmacol 2004; 68: 1049-53.

[3] Yeung K, Seitz T, Li S, et al. Suppression of Raf-1 kinase activity and MAP kinase signalling by RKIP. Nature 1999; 401: 173-7.

[4] Fu Z, Smith PC, Zhang L, et al. Effects of raf kinase inhibitor protein expression on suppression of prostate cancer metastasis. J Natl Cancer Inst 2003; 95: 878-89.

[5] Fu Z, Kitagawa Y, Shen R, et al. Metastasis suppressor gene Raf kinase inhibitor protein (RKIP) is a novel prognostic marker in prostate cancer. Prostate 2006; 66: 248-56.

[6] Al-Mulla F, Hagan S, Behbehani AI, et al. Raf kinase inhibitor protein expression in a survival analysis of colorectal cancer patients. J Clin Oncol 2006; 24: 5672-9.

[7] Minoo P, Zlobec I, Baker K, et al. Loss of raf-1 kinase inhibitor protein expression is associated with tumor progression and metastasis in colorectal cancer. Am J Clin Pathol 2007; 127: 820-7.

[8] Hagan S, Al-Mulla F, Mallon E, et al. Reduction of Raf-1 kinase inhibitor protein expression correlates with breast cancer metastasis. Clin Cancer Res 2005; 11: 7392-7.
[9] Schuierer MM, Bataille F, Hagan S, et al. Reduction in Raf kinase inhibitor protein expression is associated with increased Rasextracellular signal-regulated kinase signaling in melanoma cell lines. Cancer Res 2004; 64: 5186-92.

[10] Akaishi J, Onda M, Asaka S, et al. Growth-suppressive function of phosphatidylethanolamine-binding protein in anaplastic thyroid cancer. Anticancer Res 2006; 26: 4437-42.

[11] Lee HC, Tian B, Sedivy JM, et al. Loss of Raf kinase inhibitor protein promotes cell proliferation and migration of human hepatoma cells. Gastroenterology 2006; 131: 1208-17.

[12] Huerta-Yepez S, Yoon NK, Hernandez-Cueto A, et al. Expression of phosphorylated raf kinase inhibitor protein (pRKIP) is a predictor of lung cancer survival. BMC Cancer 2011; 11: 259.

[13] The World Health Organization histological typing of lung tumours. Second edition. Am J Clin Pathol 1982; 77: 123-36.

[14] Yeung K, Janosch P, McFerran B, et al. Mechanism of suppression of the Raf/MEK/extracellular signal-regulated kinase pathway by the raf kinase inhibitor protein. Mol Cell Biol 2000; 20: 3079-85.

[15] Yeung KC, Rose DW, Dhillon AS, et al. Raf kinase inhibitor protein interacts with NF-kappaB-inducing kinase and TAK1 and inhibits NF-kappaB activation. Mol Cell Biol 2001; 21: 7207-17.

[16] Kroslak T, Koch T, Kahl E, et al. Human phosphatidylethanolamine-binding protein facilitates heterotrimeric G protein-dependent signaling. J Biol Chem 2001; 276: 39772-8.

[17] Eves EM, Shapiro P, Naik K, et al. Raf kinase inhibitory protein regulates aurora $\mathrm{B}$ kinase and the spindle checkpoint. Mol Cell 2006; $23: 561-74$.

[18] Mountain CF. The international system for staging lung cancer Semin Surg Oncol 2000; 18: 106-15.

[19] Fukui T, Mori S, Yokoi K, et al. Significance of the number of positive lymph nodes in resected non-small cell lung cancer. J Thorac Oncol 2006; 1: 120-5. 